Fernández-Díaz, E. \& Calvo, A. (2013). Estrategias para la mejora de la práctica docente. Una investigación-acción colaborativa para el uso innovador de las TIC. Revista Electrónica Interuniversitaria de Formación del Profesorado, 16 (2), 121-133.

DOI: http://dx.doi.org/10.6018/reifop.16.2.180941

\title{
Estrategias para la mejora de la práctica docente. Una investigación-acción colaborativa para el uso innovador de las TIC
}

Elia Fernández- Díaz, Adelina Calvo Salvador

Universidad de Cantabria

\section{Resumen}

Este artículo describe un proyecto de Investigación-Acción Colaborativa dirigido a promover un uso innovador de las TIC (que conlleva un cambio real de las prácticas docentes) en Educación Infantil y Primaria a lo largo de cuatro años. Los resultados muestran las transformaciones producidas a tres niveles: a nivel curricular, organizativo y de formación permanente del profesorado. Se concluye la necesidad de seguir investigando para promover una introducción pedagógica de las TIC que vaya más allá de la dotación tecnológica, canalizando las iniciativas docentes hacia entornos colaborativos y promoviendo la reflexión sobre las estrategias que posibilitan la sostenibilidad de los cambios.

\section{Palabras clave}

Formación permanente; Investigación- Acción; innovación educativa; desarrollo profesional.

Contacto

Elia Fernández-Díaz, fdiazem@unican.es, Universidad de Cantabria. Facultad de Educación. Avda. de los Castros, $\mathrm{S} / \mathrm{N}, 39005$. Santander.

Este trabajo se ha desarrollado gracias a la financiación de la Universidad del País Vasco, UPV-EHU

(PIFA/01/05/014), en el marco de una Beca de Investigación. Las autoras agradecen el apoyo de esta institución, así como la colaboración de los Centros de Formación Permanente del Profesorado de Sevilla, Castilleja de la Cuesta y Lora del Río 


\section{Strategies to improve teacher practice. A collaborative action research towards an innovative use of ICT}

\section{Abstract}

This article is the result of a collaborative research project aimed at promoting an innovative use of the ICTs in Pre-school and Primary Education over the course of four years. The results obtained show the changes on three levels: a curricular level, an organizational level, and a continuing teacher education level. We conclude that there is a need to continue research regarding the introduction of not only technical but mainly pedagogical use of ICT, channelling the teachers' initiatives into collaborative environments in order to optimize the reflection of strategies that enable the sustainability of these changes.

\section{Key words}

Teacher training; action research; educational innovation; professional development.

\section{Introducción}

El incremento de recursos tecnológicos y la proliferación de cursos de formación permanente para su introducción en la enseñanza han acercado las tecnologías al profesorado. Sin embargo, a pesar del esfuerzo realizado, parecen todavía relativamente escasos los usos educativos realmente innovadores. En este sentido, algunos estudios han señalado la aplicación descontextualizada de las TIC en la educación, otorgando un valor elevado a la dimensión tecnológica del proceso y dejando en un segundo plano la dimensión pedagógica, organizativa y social de su uso en la enseñanza (Fundación telefónica, 2011; Gutiérrez, 2008b). Se entiende, así, que la generalización del uso de las tecnologías no ha supuesto una verdadera modificación de las rutinas pedagógicas, sino que más bien, se ha convertido en un instrumento más al servicio de la perpetuación de una cultura escolar prexistente (Area, 2011; Gewerc y Montero, 2013; Law, Pelgrum y Plomp, 2008; OECD, 2004; Sancho y Alonso, 2012; Somekh, 2008; Trigueros, Sánchez y Vera, 2012).

Aunque las tecnologías por sí solas no generen saltos cualitativos en los procesos educativos, éstas pueden contribuir a esclarecer la persistencia de prácticas tradicionales, pues los docentes ponen las herramientas al servicio de sus propósitos, por lo que parece necesario garantizar procesos de reflexión que tengan por objetivo desentrañar el papel de los conocimientos implícitos sobre la enseñanza y el arraigo de las prácticas institucionalizadas como barreras para el cambio (Ertmer, 2005; Ertmer y OttenbreitLeftwich, 2010; Totter, Stütz y Grote, 2006). En este sentido, los programas de formación docente sobre la integración de las tecnologías deben favorecer el cambio educativo mediante propuestas de intervención que partan del contexto real de los participantes, proponiendo metas que puedan integrarse en el entorno inmediato, generando dinámicas de trabajo en equipo e incidiendo en aspectos organizativos del centro (UNESCO, 2004). Se trata de establecer modelos de formación del profesorado y de investigación educativa susceptibles de garantizar la revisión y la mejora de la práctica docente a propósito de la integración de las tecnologías, garantizando la autonomía y el protagonismo de los docentes en el desarrollo e innovación curricular (Fernández Tilve y Montero, 2008).

Nuestra investigación se ha desarrollado a partir de un proceso de Investigación-Acción Colaborativa (I-AC). Se trata de una metodología que nos ha permitido impulsar la reflexión 
sobre la práctica de los participantes, contrastar ideas en la acción y generar conocimiento, a la vez que nos ha facilitado una constante revisión del diseño de la propia investigación (Kemmis, 2009; Kemmis y McTaggart, 2000; Somekh, 2006; Zeichner, 2010). Su carácter colaborativo ha permitido al profesorado desempeñar un rol más importante que el de mero informante, el de co-investigador, beneficiándose, así, de la construcción conjunta del conocimiento y de la incorporación de ciertas técnicas y procedimientos para desarrollar su propia labor de investigación en el aula. Con ello, el profesorado participa en procesos de producción y difusión del conocimiento que nacen de su trabajo diario, iniciándose un camino hacia la formación permanente vinculada con los desafíos de su práctica y con su mejora (Casals, VIllar y Ayats, 2008; Fernández Rodríguez, 2009; Herr y Anderson, 2007; Rekalde, Vizcarra y Makazaga, 2011).

Finalmente, en tanto que investigación tecnológicamente mediada, hemos podido ampliar nuestro escenario de actuación hacia otras comunidades docentes, más allá de nuestra comunidad primigenia (conformada por los profesionales que presencialmente deciden participar en la investigación). En este sentido, las características y composición de la muestra se amplía progresivamente hasta generar una red de centros y profesionales que, aunque se encuentran geográficamente dispersos, logran implicarse en proyectos colaborativos. Nos hemos ayudado de las tecnologías para optimizar el proceso crítico, reflexivo y colaborativo de la acción, así como para la recogida de datos, dado que las técnicas utilizadas se han aplicado en escenarios reales y virtuales, inspirándonos para ello en anteriores trabajos de investigación (Domaille y Buckingham, 2001; Gutiérrez, 2008a; Selwood y Twinning, 2005; Somekh y Zeichner, 2009).

\section{Objetivos de la investigación}

La investigación tuvo como propósito general crear y consolidar un entorno de trabajo colaborativo para el desarrollo y la innovación curricular, implicando al profesorado en la reflexión sobre las prácticas de integración de las tecnologías. Esta meta se ha concretado en los siguientes objetivos específicos:

- Mejorar el diseño de un entorno creativo para la reconceptualización de los usos TIC desde un enfoque curricular crítico.

- Reflexionar sobre los cambios que pueden idearse para modificar las rutinas organizativas como paso previo a la innovación.

- Analizar las pautas que deben articularse para hacer factible el andamiaje entre docentes en su alfabetización tecnológica.

\section{Metodología}

\section{Diseño: fases de la investigación}

Las fases de nuestra investigación han sido un total de tres: Sensibilización (2006), Proyectos colaborativos (2007) y Estrategias innovadoras 2.0 (2008-2010). Cada una de ellas ha estado guiada por una hipótesis-acción, entendida como una acción que provoca cambios en las prácticas y que, en su propio desarrollo, permite también generar conocimiento para mejorar cada una de las fases (Denzin y Lincoln, 2005).

La hipótesis-acción de la primera fase promovió la explicitación, por parte del profesorado, del enfoque de enseñanza subyacente a sus prácticas con TIC. La de la segunda fase estimuló la realización de proyectos colaborativos entre diferentes centros, fomentando el intercambio de reflexiones en diferentes contextos educativos (EI y EP). En la tercera y última fase la hipótesis-acción permitió consolidar las estrategias innovadoras a partir de 
proyectos colaborativos intra e intercentros, incorporando la tecnología social o Web 2.0. Se desarrollaron diferentes procesos reflexivos en torno a la realización de estos proyectos que lograron potenciar las estrategias de innovación incorporando la denominada tecnología social.

\section{Instrumento y procedimiento}

A su vez, en cada una de estas fases se desarrollaron los ciclos de Planificación, Acción y Revisión/Mejora (PAR/M), para vehicular la investigación-acción sobre el proceso formativo e introducir ajustes con vistas a obtener experiencias de transformación de la práctica de los docentes, analizar las estrategias que confieren sostenibilidad a las innovaciones y mejorar la colaboración de los participantes.

Las técnicas de recogida de datos utilizadas son las que habitualmente se usan en la investigación de inspiración cualitativa (observaciones, entrevistas, grupos de discusión, etc.), si bien estas técnicas han sido administradas tanto en escenarios reales como virtuales. El análisis de los datos fue realizado de forma paralela a la acción formativa, estructurándose un informe parcial en cada una de las fases. Las dimensiones y categorías de análisis utilizadas se elaboraron a partir de un proceso inductivo-deductivo, siguiendo la estela de otros trabajos centrados en explorar la potencialidad transformadora de la tecnología (Gewerc y Montero, 2013; Sancho y Alonso, 2012).

Un resumen de las fases y de las técnicas de recogida de datos se recoge en la figura siguiente:

\begin{tabular}{|c|c|c|c|}
\hline FORMACIC & Planificación & Acción & $\begin{array}{l}\text { Revisión y } \\
\text { Mejora }\end{array}$ \\
\hline 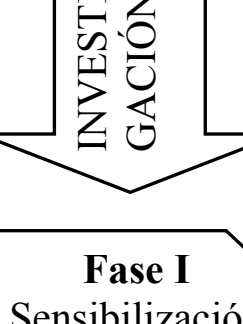 & $\begin{array}{l}\text {-Cuestionario } \\
\text { - I Formulario registro } \\
\text { de datos } \\
\text {-Foro formativo }\end{array}$ & $\begin{array}{l}\text {-II Formulario registro } \\
\text { de datos } \\
\text {-Foro feedback } \\
\text {-Observación del } \\
\text { contexto } \\
\text {-Análisis de } \\
\text { experiencias previas }\end{array}$ & $\begin{array}{l}\text {-Foro feedback } \\
\text {-Observación del contexto } \\
\text { on line } \\
\text {-Análisis experiencias } \\
\text { previas } \\
\text {-Entrevistas virtuales }\end{array}$ \\
\hline $\begin{array}{c}\text { Fase II } \\
\text { Proyectos } \\
\text { colaborativos }\end{array}$ & -Foro de seguimiento & $\begin{array}{l}\text {-Observación } \\
\text { participante } \\
\text { presencial } \\
\text {-Análisis de } \\
\text { herramientas } \\
\text { tecnológicas } \\
\text {-Foro de seguimiento }\end{array}$ & $\begin{array}{l}\text {-Observación participante } \\
\text { virtual } \\
\text {-Análisis de herramientas } \\
\text { tecnológicas } \\
\text {-Foro de seguimiento } \\
\text {-Diarios virtuales } \\
\text {-Grupos de discusión } 2.0\end{array}$ \\
\hline $\begin{array}{c}\text { Fase III } \\
\text { Estrategias } \\
\text { innovadoras }\end{array}$ & $\begin{array}{l}\text {-Informe parcial } \\
\text { - }\end{array}$ & $\begin{array}{l}\text {-Foro de evaluación } \\
\text {-Análisis de materiales } \\
\text {-Análisis de proyectos }\end{array}$ & $\begin{array}{l}\text {-Foro de evaluación } \\
\text {-Análisis de documentos } \\
\text {-Grupos de discusión } 2.0 \\
\text {-Entrevistas } \\
\text {-Cuestionarios de } \\
\text { evaluación de los } \\
\text { participantes } \\
\text {-Informe final }\end{array}$ \\
\hline
\end{tabular}

Figura I. Fases y técnicas de recogida de datos 


\section{Participantes}

La investigación comienza en el año 2006 en el centro de formación permanente del profesorado (CEP) de Castilleja de la Cuesta, Sevilla. En el inicio de la misma se encuentra el trabajo de la investigadora principal como coordinadora y ponente de un proceso formativo dirigido a docentes de la etapa de Infantil sobre el uso innovador de las TIC como contexto para provocar cambios en las prácticas docentes. Es precisamente esta acción formativa el escenario que posibilitó el desarrollo del proceso de investigación sobre la práctica, un proceso que permitió fundamentar y generalizar la integración de las TIC a través de proyectos colaborativos y que facilitó la génesis de una incipiente red de docentes de Educación Infantil de centros públicos con diferentes niveles y ritmos de profundización.

Esta acción formativa se extendería posteriormente al CEP de Sevilla (capital) y de Lora del Río en las sucesivas fases. Así mismo, tuvimos la posibilidad de contar con la participación de un centro del País Vasco (Bilbao), y de varias docentes gallegas, lográndose aumentar la cantidad y variedad de experiencias de integración de las TIC. Paralelamente, la participación de docentes de Educación Primaria en la investigación enriqueció significativamente el trabajo colaborativo. El número total de participantes en la investigación estuvo conformado por 45 tutores de El y EP de las comunidades de Andalucía, País Vasco y Galicia. Así mismo, se contó con la colaboración de los CEP de las tres localidades andaluzas citadas.

\section{Resultados}

\section{- Dimensión curricular. Negociando la integración de las TIC}

Uno de los principales resultados que hemos conseguido a nivel curricular ha sido el desarrollo de procesos de reflexión y análisis en torno a las prácticas de integración de las TIC y el diseño de propuestas alternativas de aula. En este sentido, se lograron analizar los enfoques tecnológicos y educativos que sustentaban estas prácticas, así como el grado de autonomía y el papel de los docentes en las mismas. Todo ello supuso la creación de un diálogo sobre la reconstrucción de las experiencias docentes en el seno de un grupo profesional. Una muestra de ello es la siguiente descripción de las experiencias educativas desarrolladas por un grupo docente:

"Los maestros/as realizan un montaje audio-visual sobre la actividad con aportaciones y participación de los alumnos/as. Se pretende que poco a poco sean ellos quienes las realicen. El montaje audio-visual aporta una visión global e integradora de las vivencias personales de cada alumno/a, a la vez que les permite mostrar a los demás sus experiencias (...). Además, se puede y debe aprovechar para añadir videos, enlaces y/o proponer trabajos relaciones con el tema para maximizar el aprovechamiento educativo de la actividad como son: A) Las actividades de refuerzo y ampliación/profundización de los contenidos que están trabajando en clase. Existen muchas actividades y muchos sitios donde buscarlas. Pero aquí, lo más importante, es seleccionarlas bien, introducirlas en el momento oportuno y de manera atractiva e intentar que después tengan una proyección en el aula; B) Actividades no directamente relacionadas con los contenidos de algún tema específico, juegos multidisciplinares (...); C) Producciones o propuestas propias de los alumnos/as" (Wiki Infantil investiga, centro G.A.)

En un contexto escolar donde predomina la formación en aspectos tecnológicos concebida desde modelos de arriba-abajo, optamos por caminar hacia un itinerario que invirtiera esa jerarquía. Para ello concebimos un proceso en el que el profesorado se conformara una 
identidad como miembro de un grupo docente, que se caracteriza no solamente por compartir una misma visión de la integración curricular de las TIC, sino por orientarse hacia un escenario en el que progresivamente se incrementa su creatividad y autonomía en la reconstrucción de sus experiencias y en la mejora de sus prácticas. Como muestra de ello, uno de los grupos de trabajo que se conformaron en el seno del proceso de investigación explica un proceso de escritura y trabajo colectivo:

\begin{abstract}
"Desde nuestro grupo de trabajo estamos trabajando en la etapa de educación infantil con adivinanzas, cuentos cortos, retahílas y poemas, tanto de autores españoles como inventados por los participantes (alumnado, docentes, familias). Participamos 6 colegios nacionales que podéis ver en nuestro blog (...). En este segundo trimestre estamos en la fase de buscar textos y colgarlos a través de diferentes métodos interactivos. Pretendemos que los implicados interactúen en el chat del blog y vayan dándonos pautas de qué les parece lo que vamos realizando, para mejorar poco a poco nuestro proyecto (...). Los alumnos/as de diferentes colegios empezarán a conocerse en el proceso de buscar las respuestas. En el tercer trimestre esperamos creaciones de textos nuevos, para compartirlos con el resto de colegios que deseen terminar los textos que hemos empezado" (Intervención en Foro, 12/03/09).
\end{abstract}

El uso de un espacio colaborativo abierto a todo el profesorado (con independencia de su participación en esta investigación) supone la apertura de los docentes y de su trabajo hacia contextos que van más allá de su primera comunidad de prácticas. Esto les ha permitido establecer contacto con otros docentes, intercambiar conocimiento y avanzar en la creación de una red de trabajo capaz de sobrepasar los límites espacio-temporales del aula y centro.

\title{
- Hitos organizativos. Revisión de los agrupamientos en proyectos colaborativos
}

Hemos logrado revisar y mejorar las estrategias organizativas de aula y centro gracias a la realización de los proyectos colaborativos. Estos proyectos han supuesto, en primer lugar, configurar una forma de trabajo entre los propios docentes a través de un proceso denominado de hermanamiento entre centros educativos (Fernández-Díaz, 2010). En segundo lugar, este trabajo por proyectos ha sido una estrategia metodológica dirigida a mejorar los aprendizajes de los estudiantes a través de tareas como los apadrinamientos digitales (Fernández-Díaz y Correa, 2008).

Para el desarrollo de los proyectos colaborativos inter-centros, al comienzo de cada fase del proceso formativo-reflexivo tratamos de hermanar al profesorado en un proceso de investigación que acompañe la revisión de la propia práctica para introducir mejoras. Estos proyectos (talleres inter-ciclos, la creación de rincones y talleres con las familias, etc.), tanto en el interior de un mismo centro educativo como entre diferentes centros, supusieron el aumento y la revisión de las estrategias de coordinación docente, así como una visión del cambio como algo posible, asequible y vinculado con las problemáticas docentes reales. Los proyectos constituyen una alternativa para poder romper esa dinámica escolar institucionalizada en muchas escuelas en la que un saber externo y cerrado se divide en horas de lengua, matemáticas, etc., impartidas entre las cuatro paredes del aula y, generalmente, mediante agrupamientos individuales y bajo la dirección de los libros de texto. Una muestra del desarrollo de estos proyectos es la conversación mantenida entre varias participantes a propósito de la tarea conjunta que desarrollan:

"Prof. 1. He estado revisando este nuevo blog y tiene muchas posibilidades de construcción conjunta, de participación real del alumnado en su diseño y contenido. Aunque todavía el blog tenga corta vida, creo que manejas las 
claves para ir sentando una intervención sistemática (agrupamiento mediante apadrinamiento, intervención con familias...). Prof. 2. Quedaron impactados con las cosas que son capaces de hacer sus hijos/as. Están muy motivados/as, pero el problema que veo es que no hay tanta implicación por parte de la tutora del otro curso. En fin, yo dejé muy claro que esto funciona si hay "vida" por ambos lados (...). Prof. 1. Efectivamente, tendríamos que centrarnos en la motivación de la compañera de primaria para optimizar el desarrollo de la experiencia, es importante compartir tareas, no sólo porque estás gestionando muchos blogs (...) sino porque tenemos que intentar que la otra tutora se nutra del sentido educativo de las actividades, que perciba la necesidad de cambio y mejora de su práctica" (Grupo de discusión, fase 3).

Es precisamente en este contexto de trabajo colaborativo donde llevamos a cabo estrategias de agrupamiento entre los estudiantes para mejorar sus aprendizajes. Se trata de estrategias que contribuyen a flexibilizar la organización espacio-temporal en la escuela, tales como los apadrinamientos digitales en los que se implica al alumnado de Primaria en la tutorización del de Infantil en tareas que requieren el uso de tecnologías educativas. Basado en el término "apadrinamiento lector" que alude a la relación de tutorización como estrategia para favorecer el aprendizaje de la lengua escrita (Nemirovsky, 1998), el digital abarca los procesos psicocognitivos inherentes a la tutorización, así como el establecimiento de relaciones afectivas y sociales para acompañar el acercamiento al uso de las TIC en un cálido y estimulante clima de trabajo. Un ejemplo de este tipo de tareas nos la ofrece una de las participantes a partir de la siguiente descripción de un proyecto intercentros:

"Hoy (...) hemos concretado un poco más la tarea de nuestros centros. El colegio A. realizará las ilustraciones en blanco y negro (que el alumnado coleará posteriormente) a través de dibujos que aporta el profesor sobre el cuento (...). Estas ilustraciones serán escaneadas para pasarlas al programa de presentaciones (...), [intentando] que este programa lo terminen manejando los alumnos de $4^{\circ}$ de EP (que tutorizarán a los de 5 años). Respecto al otro centro, se descargarán las imágenes de la página web: gifs animados elegidos por los propios niños/as de infantil, una vez que ellos eligen las imágenes de un mismo cuento, las ordenan creativamente y narran la historia, mientras que el tutor (niño de $4^{\circ} \mathrm{EP}$ ) transcribe lo que el pequeño les va diciendo" (Grupo de discusión, fase 3).

\section{- Cambios en la esfera formativa. Andamiaje: niveles y contextos}

En nuestra investigación hemos constatado un conjunto de resultados que dibujan una forma de entender la formación permanente del profesorado como un proceso vinculado a la práctica diaria y con altas dosis de autonomía y de participación, en la que la ayuda mutua entre docentes es un ingrediente fundamental. Tal y como señala uno de los participantes a propósito de su intervención en el congreso nacional “Internet en el Aula” (2008):

"Como docentes, el intercambio de experiencias mediante el blog nos ayuda a repensar la práctica para mejorarla. En este sentido, ha sido gratificante pertenecer a una red de centros donde el intercambio de ideas, inquietudes, nuevas herramientas, etc. te hace persistir ante las dificultades y permite desarrollar un trabajo colaborativo y enriquecedor".

En el apartado anterior planteábamos que desde el punto de vista organizativo resulta significativo el proceso de hermanamiento entre centros (ayuda y colaboración en una empresa conjunta) para el desarrollo de proyectos colaborativos, pero además, esa 
colaboración ha tomado diferentes formas y se ha expresado en distintos contextos y, también, con diverso grado de intensidad en el ámbito del desarrollo profesional y formativo de los docentes implicados. De entre todos ellos destacan los procesos de andamiaje, entendidos como procesos de ayuda entre docentes más y menos experimentados en el uso innovador de las tecnologías educativas. En este sentido, es de utilidad hacer una distinción entre niveles de andamiaje primario, secundario y terciario, entendiendo que esta escala implica una progresión en la sistematización de la ayuda, así como una mejora del reconocimiento externo a su desarrollo profesional (Fernández-Díaz, 2010).

Si bien en nuestra investigación se han desarrollado procesos de andamiaje en los tres niveles (jugando en ellos la investigadora principal un papel cada vez menos directivo), nos centraremos ahora en el terciario, por ser un nivel donde los docentes presentan un mayor grado de autonomía, incorporándose alguno de ellos al proceso de investigación como facilitadores en la última etapa de la I-AC. Este avance supone consolidar, mejorar y visibilizar la tarea de andamiaje que vienen desarrollando algunos docentes, de manera que éstos comienzan a participar en la investigación desde el rol del "facilitador", como docentes que ayudan a otros docentes en la investigación y mejora de sus prácticas. De esta forma, logramos que formalmente se otorgara una acreditación por parte de los CEP a la mejora realizada y al papel desempeñado por los docentes que hicieron de facilitadores. La importancia del papel realizado por los facilitadores puede verse en descripciones como estas:

"Todos sabemos que la Administración, cuando lleva a cabo nuevos proyectos y grandes inversiones, nunca hace un análisis de la realidad y en el caso de la integración de las TIC no valoró que la realidad en los centros (...) es que nadie nos había formado. Primero, han puesto los equipos y después nos "incitan a hacer cursos de formación". (...) Los cambios son duros y generan inestabilidad y desconcierto (...), por eso debo decir que aunque os creáis perdidos, inseguros/as y no sepáis como afrontar ciertas cuestiones, el hecho de intentarlo y afrontar nuevos métodos, supone mucho, implica querer cambiar (...). Estamos para aprender unos/as de otros/as, para compartir logros y desilusiones, para plantear dudas o para gritar lo perdidos que podemos encontrarnos: alguien ofrecerá un campo por el que empezó a caminar" (Intervención en Foro, 24/01/2009).

Por otro lado, los andamiajes acontecen en diferentes contextos o escenarios: en un mismo centro, generalmente a través de los apadrinamientos digitales y/o talleres inter-ciclos; en diferentes centros, en el contexto de proyectos colaborativos y grupos de trabajo y en la comunidad de prácticas, el entorno colaborativo virtual. Finalmente, estos también tuvieron lugar en la comunidad expandida, mediante interacciones virtuales y presenciales desarrolladas en otros contextos a propósito de la participación de los docentes en diferentes Jornadas, Seminarios y Congresos nacionales. Una síntesis de los resultados se recoge en la tabla siguiente: 
Tabla I. Resultados de la investigación

\begin{tabular}{|c|c|}
\hline $\begin{array}{l}\text { DIMENSIÓN CURRICULAR } \\
\text { ¿Cómo mejorar el diseño de un } \\
\text { entorno transgresor y creativo } \\
\text { para la reconceptualización de } \\
\text { los usos TIC desde un enfoque } \\
\text { curricular crítico? }\end{array}$ & $\begin{array}{l}\text { 1.Creación de entornos colaborativos para la reconstrucción } \\
\text { negociada de la integración curricular de las TIC. } \\
\text { 2.Creación de una identidad en la comunidad de prácticas: lo } \\
\text { pedagógico unido a lo tecnológico. } \\
\text { 3.Los participantes alcanzan un alto grado de autonomía en la } \\
\text { reconstrucción de sus experiencias. } \\
\text { 5.Elaboran proyectos colaborativos que logran modificar las rutinas } \\
\text { de aula. } \\
\text { 5.Apertura de la colaboración a contextos externos a la comunidad } \\
\text { de prácticas. }\end{array}$ \\
\hline $\begin{array}{l}\text { HITOS ORGANIZATIVOS } \\
\text { ¿Qué cambios pueden idearse } \\
\text { para romper la rutina } \\
\text { organizativa escolar? }\end{array}$ & $\begin{array}{l}\text { 1.Utilización, como pretexto, del uso de las TIC en el aula para } \\
\text { revisar las estrategias organizativas y la organización espacio- } \\
\text { temporal. } \\
\text { 2.Proyectos colaborativos entre el profesorado para favorecer la } \\
\text { investigación para la mejora en el aula. } \\
\text { 3.Desarrollo de proyectos colaborativos inter-centros entre aulas } \\
\text { geográficamente separadas. } \\
\text { 4.Aumento y revisión de las estrategias de coordinación docente } \\
\text { para hacer posible estos proyectos. } \\
\text { 5.Promoción del cambio desde la base del sistema educativo. } \\
\text { 6.Organización de apadrinamientos digitales que implican al } \\
\text { alumnado de Infantil y Primaria. }\end{array}$ \\
\hline $\begin{array}{l}\text { CAMBIOS EN LA ESFERA FORMATIVA } \\
\text { ¿Qué pautas deben articularse } \\
\text { para hacer factible el andamiaje } \\
\text { en la alfabetización tecnológica } \\
\text { del profesorado? }\end{array}$ & $\begin{array}{l}\text { 1.Desarrollo de procesos de andamiaje de primer, segundo y tercer } \\
\text { orden. } \\
\text { 2.Aumento progresivo de autonomía docente en la reflexión y en } \\
\text { su papel de investigador: desarrollo de roles de facilitador. } \\
\text { 3.Desarrollo de procesos de andamiaje en diferentes contextos: } \\
\text { intra-centros, inter-centros, en la comunidad de prácticas, en la } \\
\text { comunidad expandida. Difusión en congresos, seminarios y } \\
\text { jornadas. }\end{array}$ \\
\hline
\end{tabular}

\section{Discusión y conclusiones}

Si como ya señalara HULL (1986) los resultados de un proceso de I-A deben determinarse por las transformaciones reales producidas, tanto en ideas como en prácticas, podemos afirmar que la finalidad general de nuestro trabajo se ha conseguido en gran medida, al haber logrado implementar una acción formativa que ha posibilitado un entorno de trabajo constituido por maestros/as interesados en la integración curricular de las TIC, pretexto con el que se consigue transformar la práctica de los implicados. Hemos logrado acompañar al profesorado en un proceso de reinterpretación crítica el currículum y de la organización escolar, lo que ha supuesto elaborar propuestas novedosas de forma colaborativa y negociada. Esto nos ha permitido aportar alternativas al uso de las TIC rompiendo la lógica escolar imperante en las escuelas (Fisher, Higgins y Loveless, 2007).

Asimismo, con esta investigación se ha logrado articular un proceso formativo basado en la ayuda mutua, la colaboración y el andamiaje, provocando apoyos en diferentes niveles de intervención y en los diversos contextos en los que se desarrolla la investigación. De este modo, se ha dado lugar a saltos cualitativos en el desarrollo profesional de los docentes implicados, al conferirle al docente un rol, también, esencialmente investigador e innovador. En el proceso de análisis de la práctica docente, el profesorado más competente y experimentado comparte un proceso de construcción guiada del conocimiento en el que tiene que hacer un esfuerzo consciente e intencional por compartir las estrategias 
empleadas. En este sentido, las experiencias innovadoras, junto con sus barreras y ayudas, se hacen visibles y circulan entre los docentes, generándose, a la vez, las medidas oportunas para que estas prácticas evolucionen, se sistematicen y se haga posible la transferencia a otros contextos.

Con ello, hemos logrado constatar la idoneidad de la I-AC como metodología de trabajo docente para la mejora del desarrollo profesional, así como para articular su participación activa y crítica en la integración curricular de las tecnologías. Se trata de una forma de entender la investigación educativa como acción dirigida al cambio y la mejora de las escuelas (Sancho, 2010). Se trataría, en definitiva, de poner a la investigación educativa al servicio de la capacitación para el cambio a nivel curricular, organizativo y profesional (Fernández Tilve, Gewerc y Álvarez, 2009).

Las innovaciones conseguidas no habrían sido posibles sin la creación y mantenimiento de una comunidad de prácticas, entendida como un grupo de docentes que comparten discursos y prácticas y que viven su profesión como un proceso de aprendizaje y de resolución de problemas comunes. Sin duda, uno de los objetivos más interesantes de la investigación educativa debería dirigirse a la potenciación y mantenimiento de los intercambios y diálogos profesionales entre docentes, si como apuntan algunos trabajos, estos intercambios inciden directamente en la mejora de sus prácticas, en la eficacia de los cambios y en la calidad de la enseñanza que se ofrece (Krichesky y Murillo, 2011; López, Sánchez y Altopiedi, 2011).

\section{Bibliografía}

Area, M. (2011). "Los efectos del modelo 1:1 en el cambio educativo en las escuelas: evidencias y desafíos para las políticas iberoamericanas ordenador 1 a 1". Revista Iberoamericana de Educación, 56, 49-74.

Casals, A.; VIllar, M. y Ayats, J. (2008). "La investigación-acción colaborativa: reflexiones metodológicas a partir de su aplicación en un proyecto de Música y Lengua”. Revista Electrónica Complutense de Investigación en Educación Musical, 5 (4), 1-17. Consultado el 08-12-2010 en: http://www.ucm.es/info/reciem/v5n4.pdf

Denzin, N. y Lincoln, Y. (2005). The sage handbook of qualitative research. London: Sage Publications.

Domaille, K. y Buckingham, D. (2001). Youth media education Survey 2001. Final Report. Consultado

en: http://portal.unesco.org/ci/en/file_download.phpbda80c4d208abeb94/bc3bo2d3da 23023Survey+Report++by+Kate+Domaille.rtf

Ertmer, P.A. (2005). "Teacher pedagogical Beliefs: The Final Frontier in Our Quest for Technology Integration?" Educational Technology, Research and Development, 53(4), $25-40$.

Ertmer, P. y Ottenbreit-Leftwich. (2010). "Teacher technology change: how Knowledge, confidence, beliefs, and culture intersect". ISTE (International Society for Technology in Education), 42(3), 255-284.

Fernández-Díaz, E. (2010). Hacia una utilización innovadora de las TIC en educación infantil: una propuesta para reconstruir el currículum investigando sobre la práctica. Tesis Doctoral inédita. UPV. 
Fernández-Díaz, E. Y Correa, J.M (2008). "Integración de las TIC en proyectos colaborativos mediante apadrinamientos digitales"”. Revista Latinoamericana de Tecnología Educativa, 7(2), 57-67. Consultado el 22-02-10 en: http://campusvirtual.unex.es/cala/editio

Fernández Rodríguez, E (2009). “Aprendizaje experiencial, investigación-acción y creación organizacional de saber: la formación concebida como una zona de innovación profesional". Revista Electrónica Interuniversitaria de Formación del Profesorado, 12 (3), 39-57. Consultado el 05-04-2012 en: http://www.aufop.com/aufop/uploaded_files/articulos/1254008828.pdf

Fernández Tilve, M.D., Gewerc, A. y Álvarez, Q. (2009). "Proyectos de innovación curricular mediados por TIC: Un estudio de caso". Revista Latinoamericana de Tecnología Educativa, 8 (1), 65-81.

Fernández Tilve, Ma D. y Montero, L. (2008). "Perspectivas de asesores y profesores sobre las modalidades de formación del profesorado: un estudio de caso". Revista de Investigación Educativa (RIE), 25(2), 367-388.

Fisher, T., Higgins, C. y Loveless, A. (2007). Teachers learning with digital Technologies: a review of research and projects. Bristol: Futurelab.

Fundación telefónica (2011). Las TIC en Educación. Realidad y expectativas. Informe anual 2011. Madrid, Ariel-Fundación Telefónica. Consultado el 06-04-2012 en: http://www.fundacion.telefonica.com/es/que_hacemos/media/publicaciones/Las_TI C_en_la_Educacion2.pdf

Gewerc, A. y Montero, L. (2013). "Culturas, formación y desarrollo profesional. La integración de las TIC en las instituciones educativas". Revista de educación 362, septiembre-diciembre 2013. Consultado el 11-10-2012 en: http://www.revistaeducacion.mec.es/doi/362_163.pdf

Gutiérrez, A. (2008a). "La investigación-acción participativa como estrategia de enseñanza para los medios o alfabetización digital” en A. Gutierrez y L. Torrego (Eds), Participatory action research as a necessary practice for the 21st century society. CARN bulletin, 13, 61-67.

Gutiérrez, A. (2008b). "Las TIC en la formación del maestro. "Realfabetización” digital del profesorado". Revista Interuniversitaria de Formación del Profesorado, 63 (22,3), 191206.

Herr, K. y Anderson, G. (2007). "El docente investigador: la investigación-acción como una forma válida de generación de conocimiento". En I. Sverdlick (Coord.), La investigación acción educativa. Una forma de conocimiento y acción (pp. 34-53). Buenos Aires: Noveduc.

Hull, C. (1986). “Cómo lograr la triangulación cuando sólo hay dos en el cuadrilátero". En L. Haynes (Ed), Investigación-acción en el aula (pp. 59-66). Valencia: Conselleria de Cultura, Educació i Ciencia.

Kemmis, S (2009). "Action research as a practice based practice". Educational Action Research, 173, 463-474.

Kemmis, S. y McTaggart, R. (2000). "Participatory action research" en N. Denzin e Y. Lincoln (Ed), The handbook of qualitative research (pp. 576-606). Thousand Oaks, CA: Sage.

Krichesky, G. J. y Murillo, F.J. (2011). "Las comunidades profesionales de aprendizaje. Una estrategia de mejora para una nueva concepción de escuela". REICE. Revista 
Iberoamericana sobre Calidad, Eficacia y Cambio en Educación, 9 (1), pp. 65-83. Consultado el o9-05-2012 en: http://www.rinace.net/reice/numeros/arts/volgnum1/art4.pdf.

Law, N., Pelgrum, W.F y Plomp, T. (Eds) (2008). Pedagogy and ICT in schools around the world: findings from the SITES 2006 Study. Hong Kong: CERC and Springer. Consultado el 10-10-2012 en: http://sites2006.cite.hku.hk/SITES2006-citeSeminaro80310.pd

López, J., Sánchez, M. y Altopiedi, M. (2011). “Comunidades profesionales de práctica que logran sostener procesos de mejora institucional en las escuelas". Revista de Educación, 356, 109-131.

Nemirovsky, M. (1998). El aprendizaje de la lengua escrita a través de la interacción. Barcelona: Graó.

OECD (2004). Education at a glance 2004. París, CERI-OECD.

Rekalde, I., Vizcarra, M.T. y Makazaga, A. (2011). "La aventura de investigar. Una experiencia de investigación-acción participativa”. Aula Abierta, 39, (1), 98-104.

Sancho, J.M. (2010). "Del sentido de la investigación educativa y la dificultad de que se considere para guiar las políticas y las prácticas". REICE. Revista Electrónica Iberoamericana sobre Calidad, Eficacia y Cambio en Educación, 8 (2), 34-46. Consultado el 19-09-2012 en: http://redalyc.uaemex.mx/redalyc/pdf/551/55114080003.pdf

Sancho, J.M. y Alonso, C. (2012). La fugacidad de las políticas, la inercia de las prácticas. Barcelona: Octaedro.

Selwood, I. y Twining, P. (2005). Action research and ICT. Coventry: Becta.

Somekh, B. (2006). Action research: a methodology for change and development. Buckingham: Open University Press.

Somekh, B. (2008). "Factors affecting teacher pedagogical adoption of ICT". En J. Voogt y G. Knezek (Eds), International handbook of information, technology in primary and secondary education (pp. 449-460). New York: Springer.

Somekh, B. and Zeichner, K. (2009). "Action Research for Educational Reform: remodelling action research theories and practices in local contexts". Educational Action Research, 17 (1), 5-21.

Totter, A., Stütz, D. y Grote, G. (2006). "ICT and schools: Identification of factors influencing the use of new media in vocational training schools". The electronic Journal of $e$ learning 4 (1), 95-102.

Trigueros, F.J.; Sánchez, R. y Vera, M.I. (2012). "El profesorado de Educación primaria ante las TIC: realidad y retos". Revista Electrónica Interuniversitaria de Formación del Profesorado (REIFOP), 15(1), 101-112. Consultado el 11-06-2012 en: http://www.aufop.com/aufop/uploaded_files/articulos/1335399123.pdf

UNESCO. (2004). Las tecnologías de la información y la comunicación en formación docente. París: Informe UNESCO. Consultado el 20-02-2012 en: http://unesdoc.unesco.org/images/0012/001295/129533s.pdf

Zeichner, K. M. (2010). La formación del profesorado y la lucha por la justicia social. Madrid: Morata. 


\section{Autores}

Elia Fernández Díaz

Es maestra, psicopedagoga y Doctora por la Universidad del País Vasco. Actualmente es profesora del Departamento de Educación de la Universidad de Cantabria (Área de Didáctica y Organización Escolar). Ha trabajado como docente en Educación Infantil y ha colaborado como formadora del profesorado en el CEP de Sevilla y provincia. Entre sus líneas docentes e investigadoras destacan las siguientes: tecnología educativa, investigación e innovación en educación, formación permanente, innovación en docencia universitaria y desarrollo curricular. Es miembro de la Collaborative Action Research Network (CARN) y de la Red Universitaria de Tecnología Educativa (RUTE). Entre sus publicaciones destacan diferentes artículos y capítulos de libro así como contribuciones a congresos nacionales e internacionales sobre las líneas de investigación descritas.

\section{Adelina Calvo Salvador}

Es doctora en Ciencias de la Educación por la Universidad de Oviedo. Actualmente trabaja como profesora en el Departamento de Educación de la Universidad de Cantabria (Área de Didáctica y Organización Escolar). Entre sus líneas docentes e investigadoras destacan las siguientes: Investigación cualitativa en educación, Dinámicas de Inclusión-Exclusión Socioeducativa, Procesos de Participación y Mejora en la escuela y Género y Educación. Ha participado en varios congresos nacionales e internacionales y ha publicado artículos en revistas españolas (Revista de Educación, Profesorado, etc.) y extranjeras (International Journal of Inclusive Education, Gender \& Education, etc.). Ha sido co-editora de varios libros sobre educación, exclusión y género (editoriales Icaria y Narcea) en los que ha participado también como autora de varios capítulos 